\title{
MAKING TOD IMPLEMENTABLE IN INDIAN CITIES \\ From Theory to Practice
}

Jyoti Vijayan Nair, NIUA; India

\begin{abstract}
India's staggering economic growth in the past decade and the unpredecented rate of ubanisation call for solutions that go beyond the paradigm of traditional planning. Transit Oriented Development (TOD) is widely acknowledged as the solution to sprawl, longer commute distances and carbon emissions-problems that are typical of rapidly urbanising economies. However, TOD has largely been a buzzword in Indian policy documents for over a decade, as the country still awaits its first fully implemented TOD project. This paper studies three key TOD proposals in the megacities of Delhi, Mumbai and Ahmedabad and aims to examine their approaches for want of an effective framework to evaluate the feasibility of TODs across the country.
\end{abstract}

\section{Keywords}

TOD, Redevelopment, Implementation, Policy

\section{Background}

\subsection{TOD in India}

Much like their European counterparts, traditional Indian cities are characterised by compact, high-density inner cores, which continue to thrive as major activity hubs even today in many cities like Delhi, Ahmedabad, Hyderabad, Madurai, etc. With the advent of the motor vehicle, city planning evolved to pave way for carriageways and planned development, the way we understand it today. Although western town planning principles made their way to create some of the first planned cities in India like Chandigarh, Bhubaneshwar, Gandhinagar, the impact of centuries of colonisation and exploitation did not wear away easily. Consequently, a crippled economy post-independence was unable to cope up with the pace of urbanisation, and issues relating to rural and refugee migration. Seven decades after independence, India is now home to 5 megacities with a population over 10 million (Nations, 2018), and is slated to overtake China as the most populous country in the world by 2027 (United Nations, 2019). As a result of the State's inability to meet housing demands, Indian cities now face a dire space crunch as informal settlements occupy a major chunk of prime city land. Yet, building norms have not evolved to adapt with the challenges of an exploding population, as most cities continue to follow outdated planning regulations that were imported from car-driven western economies in the 60s. Land-based zoning, minimum setback norms, parking minimums and other such regulations exacerbate issues relating to sprawl and longer commute distances. Latest available government data (MoSPI, 2015) shows that Delhi has the highest number of registered private motor vehicles in the country, followed by Bengaluru, Chennai, Ahmedabad and 
Mumbai (see Figure 1). Besides increasing dependence on cars, these vehicles occupy a major chunk of city space in the form of on-street and off-street parking, which can otherwise house the urban poor. A study reveals that 'the annual demand for additional parking spaces for cars can be equivalent to as much as 471 football fields in Delhi, 100 in Chennai, 58 in Chandigarh, and 179 in Gurgaon' (Rowchowdhury et al., 2018). Clearly, land utilisation has to be managed in a more efficient and democratic way, if Indian cities aspire to meet future housing demand.

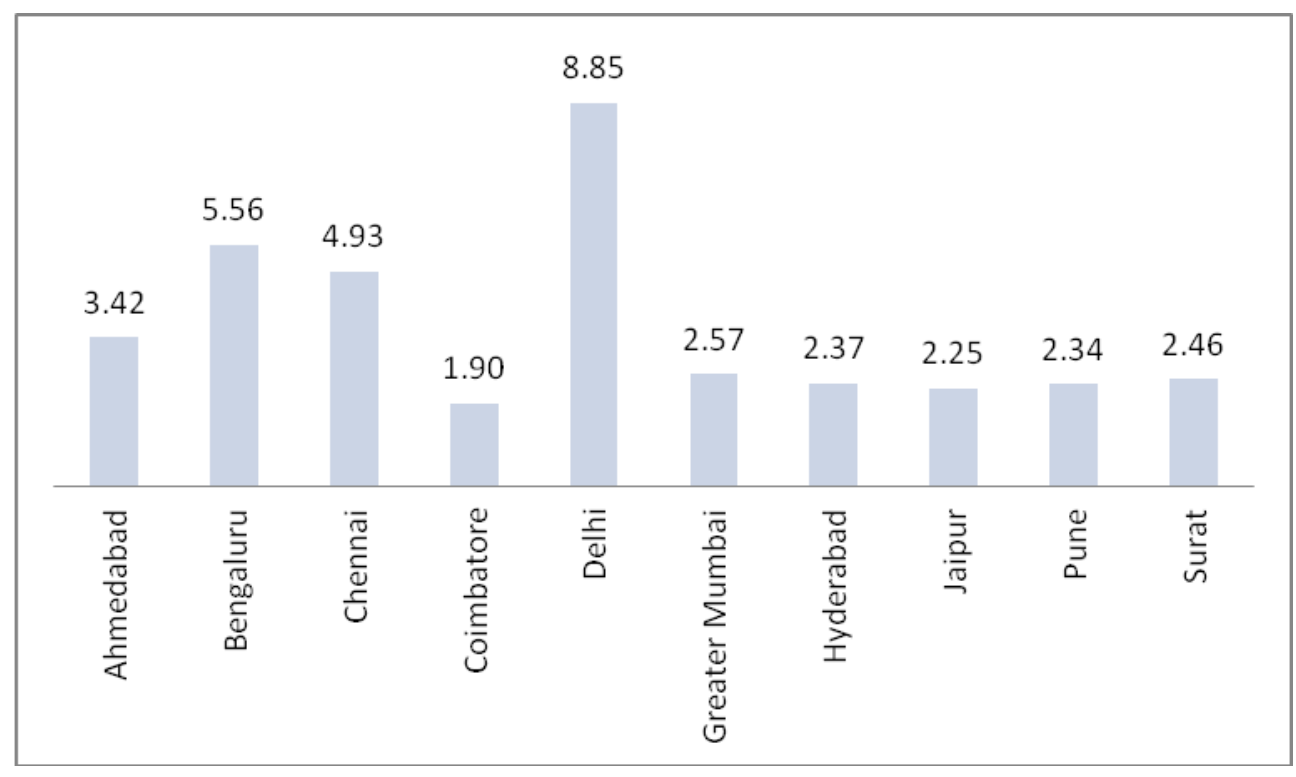

Figure 1. Top 10 Cities with maximum number (in millions) of Registered Motor Vehicles (Source : Ministry of Statistics and Programme Implementation, 2015)

The need for reducing sprawl and vertical mixing is increasingly being acknowledged in the Indian urban policy context. Learning from their Eastern neighbours like Tokyo, Singapore and Hong Kong, Indian cities are realising the potential of Transit Oriented Development (TOD) as the way forward for rapidly urbanising developing economies. TOD encourages high density, mixed-use living environments that bring live, work and leisure closer to transit, thereby eliminating the need for personal vehicles and thus promoting active travel. Urban practitioners believe that the design principles of TOD coupled with democratic land assembly mechanisms and innovations in project finance could give our cities the much needed makeover and promote sustainable mobility.

\subsection{Emerging Policy Climate}

The policy climate in the past decade has been in favour of encouraging TOD, as central and state governments are exploring various models to make TODs implementable. The country's first draft TOD Policy for the city of Delhi was released in 2012 (DDA, 2012), as an addendum to the Master Plan Delhi-2021. It was notified with many revisions in 2015 (DDA, 2015), and is being further refined in 2019, as it awaits final notification. The Ministry of Urban Development (MoUD) also released the National TOD Policy (MoUD, 2017) as a guideline for all states to formulate their respective state-specific TOD policies. The states of Jharkhand and Madhya Pradesh now have a policy framework in place, while cities like Ahmedabad, Kochi, and Bangalore have attempted to incorporate TOD in their Master Plans. However, barring the advanced stage of resolution of Delhi's TOD policy with clearly defined institutional setups and plot assemblies for brownfield redevelopment, TOD policies for 
most cities just about preach universal principles of urban design as 'special norms' for TOD Influence Zones ${ }^{1}$. Replicating urban design guidelines in the name of state policies without contextualisation or devising of appropriate institutional structures does not help enable TOD as implementable projects.

Numerous TODs are being proposed countrywide, however it's realisation on ground is largely hit-and miss. Delhi's first TOD- the East Delhi Hub at Karkardooma Metro Station was a major proposal by the Unified Traffic and Transportation Infrastructure (Planning and Engineering) Centre (UTTIPEC), that did not fructify amidst much hue and cry, and disagreements between government agencies (Sabikhi, 2016). The website of the Directorate of Urban Land Transport (DULT), Bangalore mentions many proposals including the TOD pilot project for Navnagar, Hubli. However, none of these exist on ground. From a TOD Zone parking management perspective, the World Resources Institute (WRI) studied Ghatpkopar Suburban Rail station area in Mumbai to make recommendations to the Mumbai Development Plan (Rangwala et al., 2014), while a station area accessibility proposal for Indiranagar Metro Station in Bangalore was made as early as 2011 (EMBARQ, 2011). Unfortunately, these too stand as unimplemented academic exercises.

The only promising example of TOD implementation on ground is that of Ahmedabad's proposed Central Business District, wherein the Ahmedabad Urban Development Authority (AUDA) delineated TOD corridors in the last Master Plan and used Gujarat State's progressive land reconstitution mechanism- the Town Planning (TP) Scheme to develop land for brownfield redevelopment. Despite the technical delays in plan preparation (TNN, 2017), if implemented, the CBD will be the first successful example of brownfield TOD in the country.

\subsection{Gaps in Implementation}

Multiple reasons are attributed to the colossal failure of TOD in India. Firstly, TOD is largely misunderstood as a tool to increase Floor Area Ratio (FAR) only, while the aspects of integrated mobility, more public spaces, accessible greens, active street frontages, and minimal parking are sidelined. Ahmedabad's norms relating to Urban Design (setback, building heights, active frontages), permissibility of uses and parking in the TOD notified zone, are the same as across rest of the city (AUDA, 2015). This defeats the purpose of creating a special compact and walkable TOD Zone.

Secondly normative Masterplans lack the dynamism that can adapt to demand, and often tend to dissociate themselves with on-ground realities relating to land ownership and size of plots. Delhi's TOD policy (DDA, 2015) attempted to address this issue by devising bottomup plot assembly mechanisms and appropriate institutional setups. However, putting this enabling framework in place itself took 7-8 years.

Lastly, the biggest issue with TOD policies is that the norms are uniformly applicable across all TOD station areas, irrespective of context. A blanket policy across transit stations having significantly different urban conditions is unlikely to fructify without a context-specific action plan. Recognising this gap, Delhi's upcoming revised TOD policy pushes for a phased implementation of TOD on selected nodes instead of the city as a whole (Chitlangia, 2019).

\footnotetext{
${ }^{1}$ typically delineated as either nodes/circles of $500 \mathrm{~m}$ radius around metro stations or corridors of $500 \mathrm{~m}$ on both sides of Bus Rapid Transit Systems
} 
This welcome move is not only an opportunity to identify nodes with high potential but also determine a distinct vision for each node, that will aid in the city's image-making process. TOD policies for other cities are yet to reach this level of streamlining.

\subsection{Aim}

This paper aims to explore a mechanism for cities to assess feasibility of TOD at a given station before a detailed proposal is drafted. It advocates a process of station area selection using a broad set of indicators that can help classify stations into categories of high, medium and low potential for TOD and therefore assist policy-makers in decision making. The methodology will not only provide a framework to predict the success or failure of a potential project, but will also assist in building a case for TOD at a given station.

One of the key conclusions that the paper aims to arrive at is a set of observations on the scope of TOD in densely populated core-city regions versus the sparsely developed periurban regions. Broad thumb rules for the development of these may help public and private players understand potential areas for investment and hence work out the economics for such projects.

\section{Literature Review}

\subsection{TOD Zone Delineation}

In the case of cities like Tokyo, Hong Kong and Singapore, that are globally acknowledged best practices in TOD, development follows transit and therefore station areas naturally tend to be transit-oriented. Tokyo's strategy of allowing private rail companies to readjust land in greenfields and creating new towns around expanded railway lines, coupled with redevelopment of large parcels of city land around stations, are well-regarded lessons in land assembly and brownfield redevelopment (Suzuki et al., 2013). Hong Kong on the other hand, followed the successful Rail+ Property model (see Fig 2.) wherein the government grants MTR-the privately run railway company, property development rights for station areas at 'before development' market rates. MTR in turn prepares the master plan and codevelops the station area with the developers, while sharing the profit with them on an after-development' market rate (Cervero and Murakami, 2008).

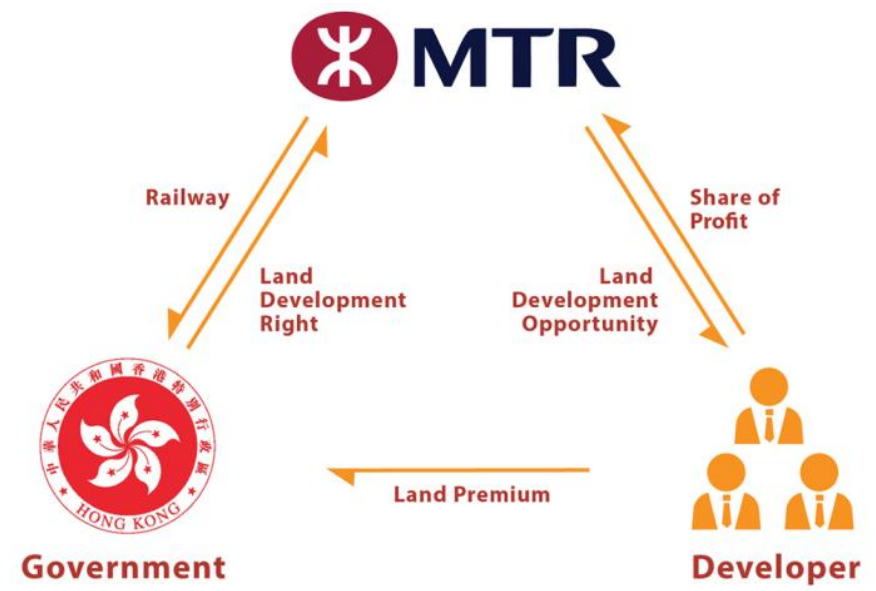

Figure 2. Hong Kong's Rail + Property Development Model (Source : MTR) 
In the case of Singapore, since $90 \%$ of land is owned by the government through acquisition under the Land Acquisition Act of 1967, subsidised public housing by Housing Development Board (HBD) has always been planned around transit stations as shown in Fig 3. As a result, $82 \%$ of Singaporeans have access to affordable housing around high capacity transit (Bin and Naidu, 2014).

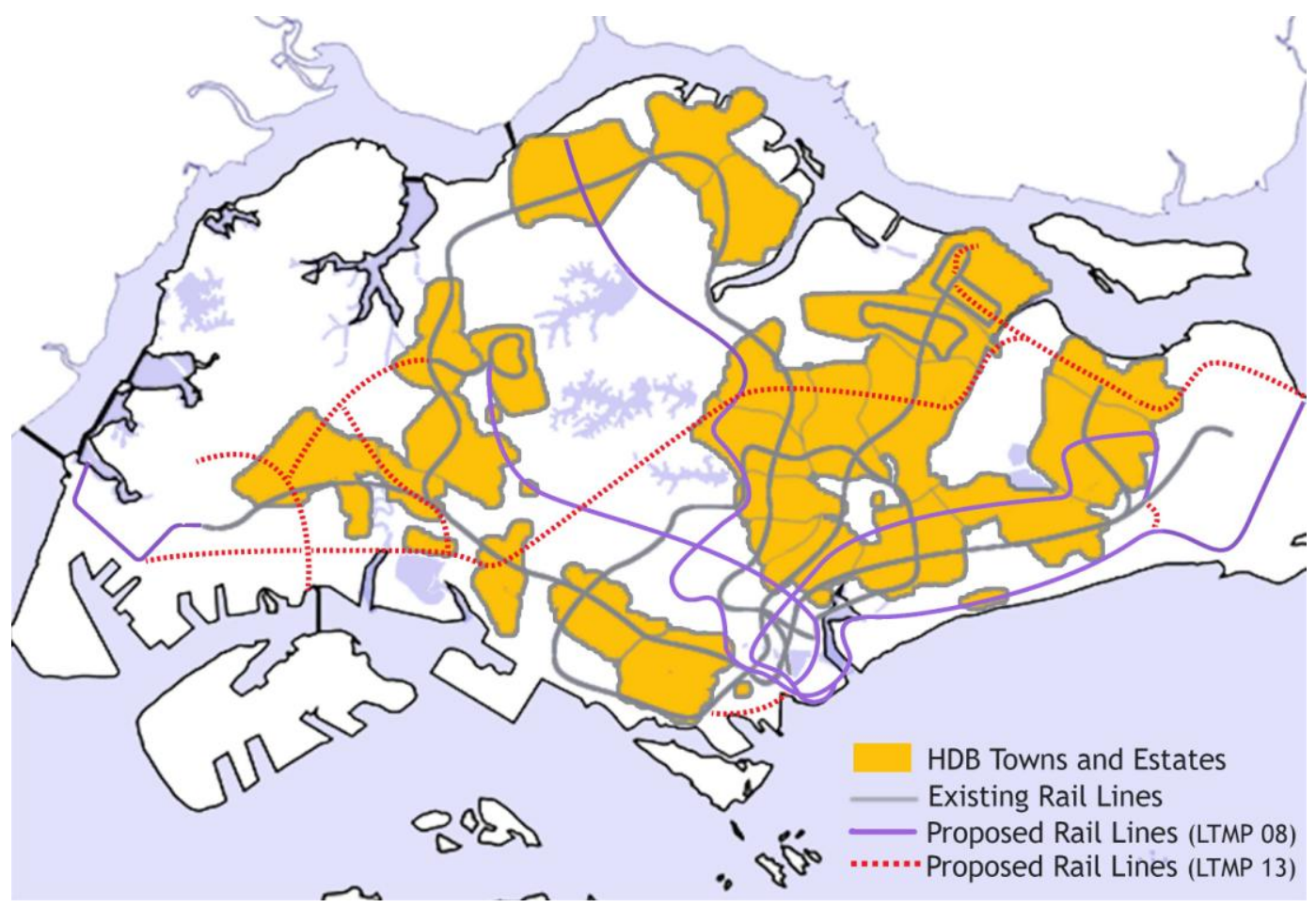

Figure 3. Singapore's Railway Lines vs Public Housing Pockets (Source : Housing Development Board)

In most Indian cities except Mumbai and Kolkata, mass transit has only been a recent development ${ }^{2}$ unlike in the case of Tokyo, Hong Kong, and Singapore. Therefore TOD in India is mostly imagined as a brownfield redevelopment process, as transit follows development in areas that generate maximum revenue to easily finance the system. The major critique of this however, is a total lack of station area planning, poor accessibility and a lack of integration between different modes of transfer from stations, primarily because land around stations is owned by mutiple entities (Agarwal et al., 2019). As a result, transit is essentially an afterthought instead of being the primary planning strategy. Since its very first Master Plan for 1981, to the last for 2021, Delhi's Master Plan almost never addresses land use and transport integration as a core strategy, even as the Delhi Metro Rail Corporation (DMRC) made its first line operational in 2002.

Acknowledging this issue, the TOD policies therefore, act as an addendum to the process of planning, wherein a certain catchment zone around transit stations/ corridors are delineated and notified as areas of special development, with norms that are different from the rest of

\footnotetext{
${ }^{2}$ Although Mumbai's Suburban railways and Kolkata's trams have existed since 1853 and 1873 respectively, Mass Rapid Transit as we know it today has existed only since early 2000s. Delhi Metro became operational in 2003, Ahmedabad's Bus Rapid Transit System- Janmarg, began operations in 2009 while Bengaluru's Metro became operational in 2011, followed by Mumbai in 2014, Jaipur and Chennai in 2015, and so on.
} 
the city. In Ahmedabad, this zone is a $400 \mathrm{~m}$ wide corridor on either sides of the Bus Rapid Transit (BRT) System. In the case of Delhi, the delineation is at a node of $500 \mathrm{~m}$ radius around Mass Rapid Transit (MRT) Systems or Metro. For National Capital Region (NCR)'s regional rail that connects 5 neighbouring cities to Delhi, TOD Zone is imagined as a node of $1 \mathrm{~km}$ around stations. The difference in the principles of these delineations depend on the perceived impact of the type of transit system on its surrounding areas. Although the corridor/ nodes are notional boundaries, the actual TOD Zone is determined by local land uses and road layouts (see Fig 4.)
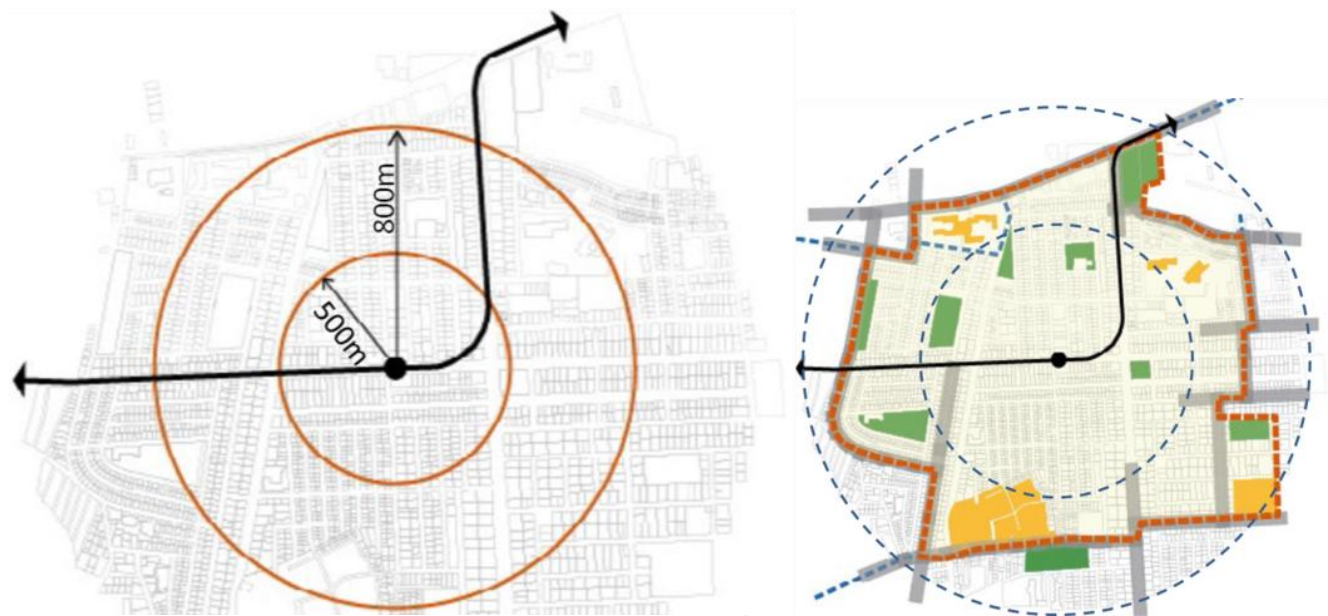

Figure 4. TOD is planned around $500-800 \mathrm{~m}$ notional circle, the exact boundaries of which are determined by existing road layout and land uses (Source : National Institute of Urban Affairs)

Once the zones are delineated, appropriate institutional setups and plot assembly mechanisms need to be put in place to facilitate large scale redevelopments based on the design principles of TOD mandated through special development control norms as outlined in the TOD policy.

\subsection{Design Principles of TOD}

There are various available definitions and principles of TOD through various national and international policies, literature and standards. According to the Institute for Transportation and Development Policy (ITDP), "Transit-Oriented Development stands for the rights of all to access the city: to walk and cycle safely, to easily and affordably reach the most distant destination through rapid and frequent transit, and to live a good life, free of dependence on cars. It stands for access to opportunity, education, services, and all the resources available via no- or low-cost mobility options." (ITDP, 2017). Through mixed-use developments, compact and high density living environments, it emphasises on eliminating the need to make trips and saving commute time and money. Cervero and Kockelman in 1997 identified three "Ds"- Density, Diversity, and Design as essential components of transit-oriented development (Cervero and Kockelman, 1997), to which Cevero later added Distance to Transit and Destination Accessibility. The MoUD's National TOD Policy (MoUD, 2017) goes a step further and outlines 'Guiding Principles' that are primarily from a design perspective (Complete Streets, Multimodal Integration, Last Mile Connectivity, NMT network, Traffic Calming, Mixed Lane Uses, Optimised Densities, Street-Oriented Buildings, Managed Parking, Informal Sector Integration, and Housing Diversity), and 'Supporting Principles' that are from an implementation perspective (engage Private Sector, Land Value Capture, Right Size 
Infrastructure, Technology Integration, High Quality Transfer System, Barrier-free Environment and Preserved Open Spaces).

ITDP's TOD Standard outlines the following eight core principles of urban design, each supported by specific performance objectives and easily measurable indicators, or metrics. The tool can be used to evaluate projects for their 'TOD-ness' (Joshi et al., 2017) and propose recommendations for their improvement, albeit strictly from a design perspective.

1. Walk : Through adequate and shaded sidewalks, pedestrian crossings and active frontages.

2. Cycle : Through a well connected cycling network and access to safe cycle parking.

3. Connect : Through smaller block sizes, a tight grid of vehicular and pedestrian network.

4. Transit : Through easy accessibility to Transit stations.

5. Mix : Through an adequate mix of commercial, residential and recreational uses with a component of affordable housing.

6. Densify : Through higher FAR and planned density (persons per hectare).

7. Compact : Through adequate adjacencies and various transit options.

8. Shift : Through on-street and off-street parking management.

However, there is a growing concern about TOD being misunderstood as merely 'TransitAdjacent Development (TAD)' than actually being Transit-Oriented (Joshi et al., 2017). The proposals by Indian Railway Station Development Corporation (IRSDC) to develop railway land near select stations as high density commercial and residential hubs, is although being hailed as an example of successful TOD implementation (Das, 2019), the extent of its adherence to TOD principles is something that remains to be evaluated. Besides, most cities still rely on archaic building norms that are contradictory to the very principles of TOD. For example regulations like mandatory provision of front setbacks, parking minimums for each plot, no norms for an integrated street network, active frontages and prohibition of boundary walls, etc. defeat the purpose of creating compact and walkable TOD neighbourhoods that promote Jane Jacob's idea of 'Eyes on the Street' .

\subsection{Land Assembly Mechanisms}

Unlike in the case of Singapore, majority of land in India is privately owned. Therefore, redevelopment for TOD purpose is conventionally done by public acquisition of land. The National Land Acquisition Act (Right to Fair Compensation and Transparency in Land Acquisition, Rehabilitation and Resettlement (RFCTLARR), 2013), which enables compulsory acquisition of land, is the primary tool to acquire land in India for public purposes ${ }^{3}$ (Mathews et al., 2018). However, the costs involved in acquisition are high and the means to finance such projects are still being explored through fiscal and non-fiscal measures. Secondly, delays in procuring land through RFCTLARR has also led state-based agencies to frame alternate land assembly mechanisms (Nair, 2016) like Land Readjustment, Land Pooling, PPP, market price negotiations, land lease policies, etc.

These alternative frameworks are deemed more progressive and bottom-up in their approach, as they provide the land owners with incentives like higher FAR and relaxation on

\footnotetext{
${ }^{3}$ The Act is a revision to the traditional National Land Acquisition Act of 1894, which was repealed due to issues relating to unfair compensation to land owners and 'severe imbalance of power between the state and the land losers' (Wahi, 2018).
} 
certain norms to make redevelopment a financially viable and profitable option. This categorically means land owners have a choice to form a consortium and amalgamate plots if they want, without mandating land surrender as the only option, as in the case of land acquisition. The government's involvement is limited to infrastructure provision for the new development, in return for a certain percentage of land for public uses such as affordable housing and public green spaces (as in the case of land readjustment). This ensures that even smaller plot are compensated in some way or the other, say through a smaller dwelling unit but with a much higher market value. Needless to say, this is a gradual process and requires a lot of consensus building between land/ property owners.

One of the earliest methods in land readjustment or reconstitution in India was the Town Planning Scheme (TPS) which was introduced through the landmark Gujarat Town Planning and Urban Development Act, 1976 (Ballaney, 2008). The TPS mechanism has been used extensively for the provision of serviced land for development, especially in the peri-urban areas of Ahmedabad. While this mechanism has largely been successful in the peripheries, its success in the urban cores is often contested due to apprehensions regarding carrying capacity of existing infrastructure to support high densities (Dutta, 2015). The entire delineated TOD zone around Ahmedbad's BRT System, as well as the proposed CBD of Ahmedabad rely on the TPS Scheme.

Delhi's TOD Policy (DDA, 2015) uses a similar bottom-up approach wherein individual plot owners within the TOD zone can voluntarily amalgamate plots, partner with developers to form the 'Developer Entity' and redevelop into large scale TOD projects that follow special TOD norms as outlined in the policy. A small percentage of the land is returned to the Development Authority for provision of public greens, as is $50 \%$ of the mandatory affordable housing units developed as per the norms. Although the urban design regulations align with the TOD principles, it may take more than just a few years for the idea of redevelopment to percolate into Delhi's real estate market. A way to expedite the process could be through implementing TOD in government-owned lands, as pilot demonstration projects (as was intended through the East Delhi Hub Proposal at Karkardooma Station in Delhi). However, a high quality TOD requires high capital investment and is not possible without the intervention of the private sector. Cities must explore similar strategies to select pilot station areas and devise appropriate financing and institutional setups for land assemblies, in order to put TOD on the fast track.

\section{Methodology}

\subsection{Conceptual Framework}

Clearly, the concept of TOD in India is past its nascent stage. It's design principles and benefits are clearly acknowledged, as is evident from various projects and government policies. Often projects are conceptualised and undergo various design iterations for months/ years, without fructifying on ground due to practical reasons like land ownership and assembly frameworks, project financing, and sometimes, even unforeseen negative impacts on existing urban context. The objective of this paper is :

- to identify criteria or parameters that impede TOD implementation on ground, and 
- to develop a framework that can help assess the feasibility of a TOD project at various stages of its inception, i.e. Pre-Planning, During Planning and PostPlanning.

This will be done through a case study of the following three TOD proposals from different contexts, that have made news in the urban development fraternity.

1. Proposed Central Business District (CBD), Ahmedabad; (Status : Under Implementation)

2. Railway Station Development, Habibganj-Bhopal; (Status : Approved by Implementing Authority)

3. Karkardooma Metro Station Development, Delhi; (Status : Not Approved by Implementing Authority)

For the first two phases (Pre-Planning and During Planning), the paper uses methods like Spatial and Quantitative Analysis of the three projects using Master Plans of the proposal, context study on satellite imagery, and a review of development numbers/area statements from the proposals. The last phase (Post-Planning) involves a review of available literature on state-specific TOD Policies, Development Model, and Institutional Setup (See Fig. 5).

\subsection{Scoring}

The projects are scored on the basis of these criteria- the underlying principle being that each phase carries equal weightage (5 points each). The criteria under each phase carry equal points - 1.66 each in the 'Pre-Planning' Phase, 1 each in the 'During Planning' Phase, and 2.5 each in the 'Post-Planning' Phase. Finally, the project that scores between $1-33 \%$ is deemed Low Probability TOD, $33-66 \%$ is Medium Probability TOD and $66-100 \%$ is High Probability TOD. 


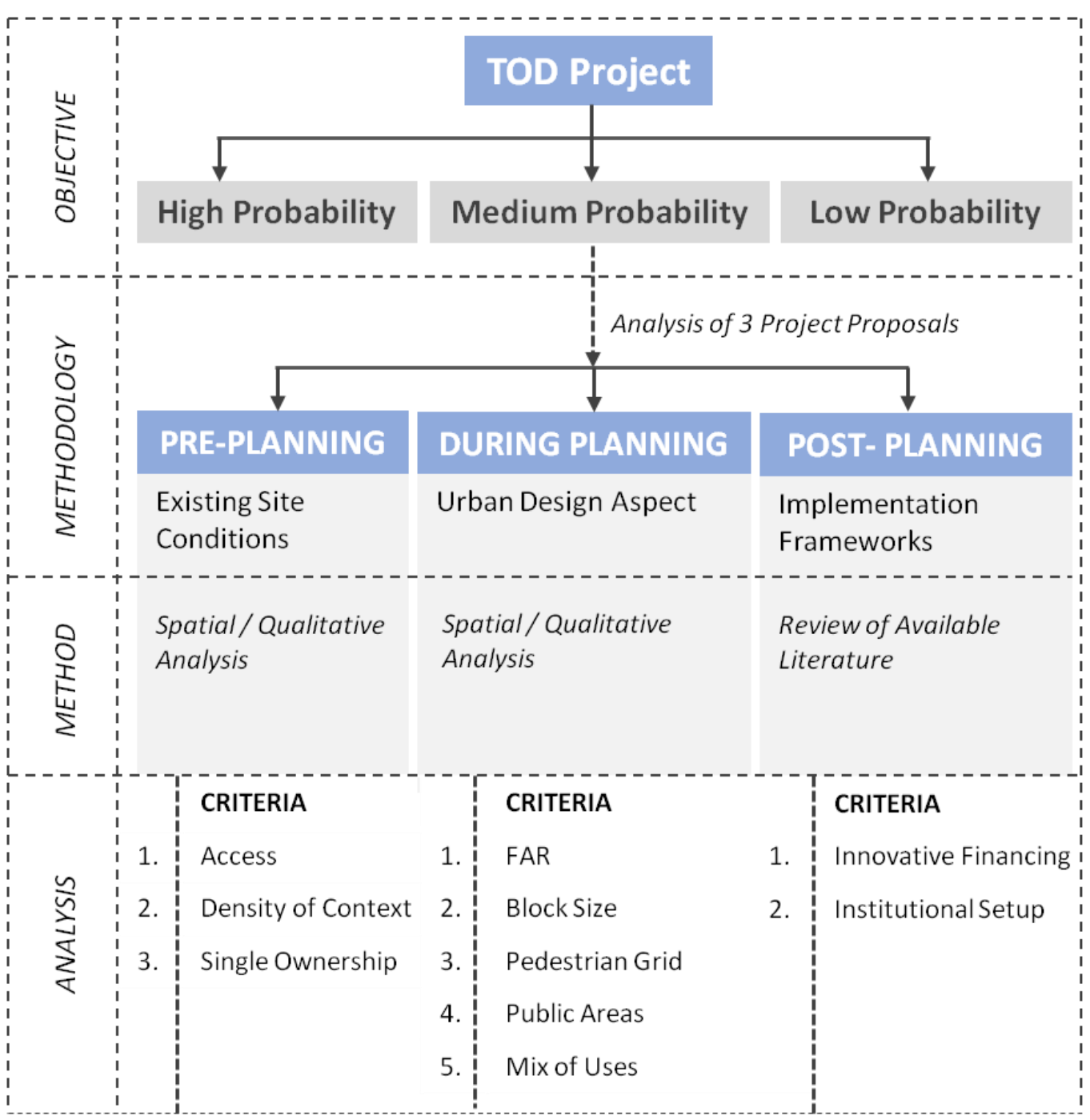

Figure 5 Conceptual Framework

The scoring however, is limited to establishing only a qualitative framework for a quick and initial TOD Project Feasibility Assessment. It does not analyse details such as Parking Numbers, detailed Distribution of Proposed Uses, Affordable Housing Units, etc. due to data unavailability. The scoring will have to be read in conjunction with policy climate, nuances in land ownership and the political will to implement TODs. Besides, for the 'During Planning' phase, there are already well-established comprehensive set of National (MoUD National TOD Policy) and International indicators (ITDP TOD Standard 3.0) as discussed earlier, which require a bigger and more detailed study, and is beyond the scope of this paper.

\subsection{Analysis of TOD Proposals}

The three projects have been analysed on the basis of the conceptual framework in tabular form, as mentioned in Fig. 6. 


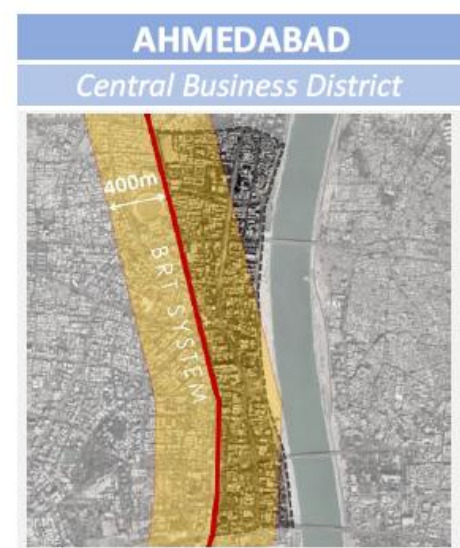

Area : $125 \mathrm{Ha}$

Type of Transit : BRT System

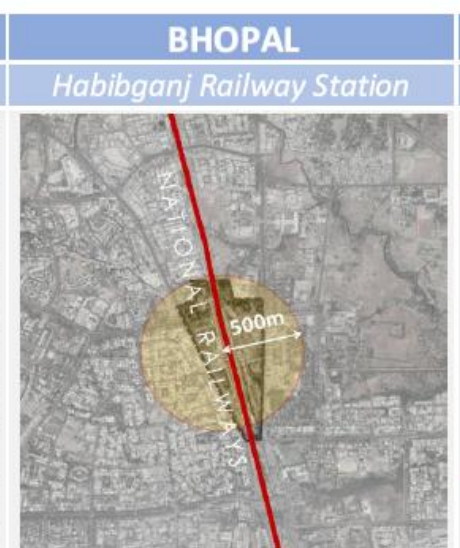

Area : $29.6 \mathrm{Ha}$

Type of Transit : National Railways

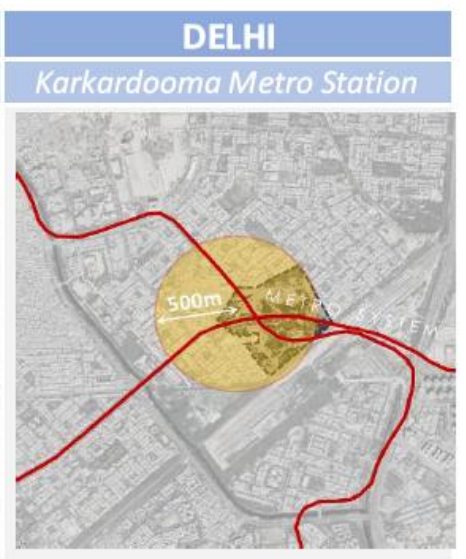

Area : $28.8 \mathrm{Ha}$

Type of Transit : Metro Station

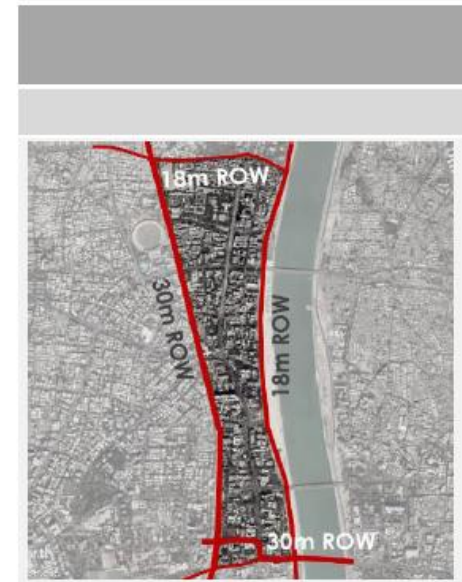

Access from all 4 sides :

$30 \mathrm{~m}$ road from two sides, and $18 \mathrm{~m}$ road from other two sides. sides.

\section{PRE-PLANNING}

\section{ACCESS}

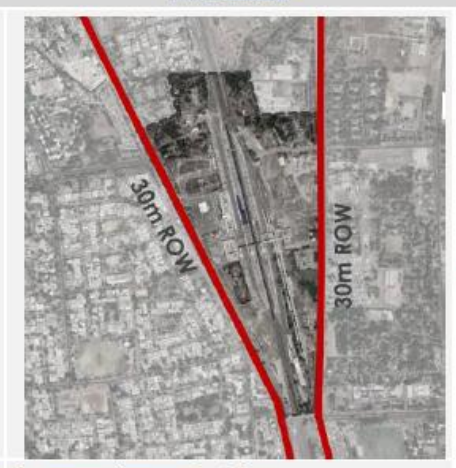

Access from 2 sides :

both $30 \mathrm{~m}$ road on opposite

\section{SURROUNDING DENSITY}

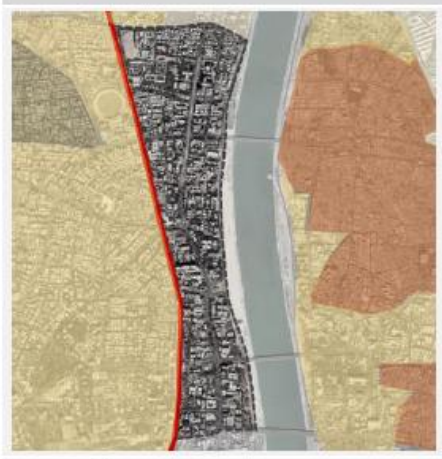

Legend:

Medium Density

High Density

Very High Density

Low Density

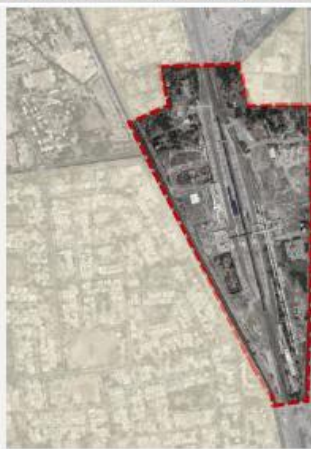

Legend:

Low Density

Very Low Density

Very High Density

Undeveloped Land

Mostly surrounded by medium density

Mostly surrounded by low to
very low density

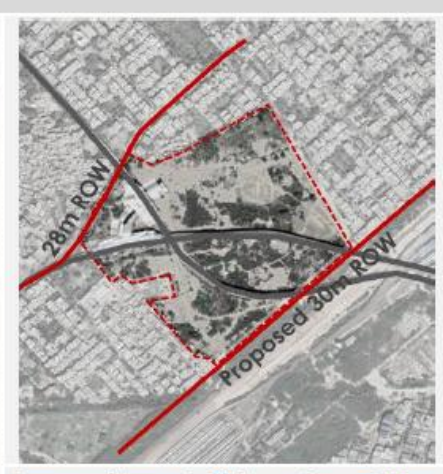

Access from 1 Side exists : $28 \mathrm{~m}$ road and proposed $30 \mathrm{~m}$ road access from the opposite side 


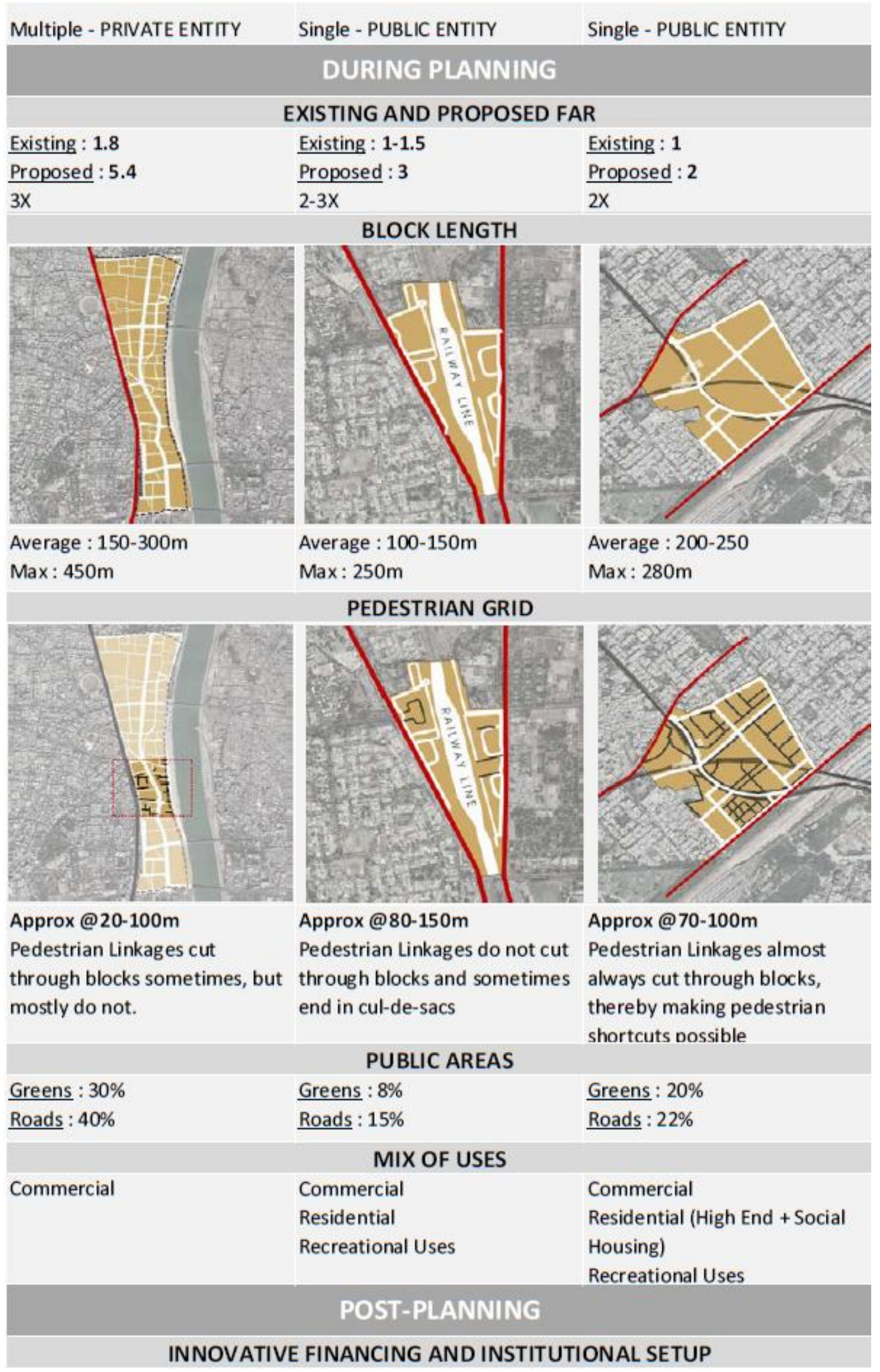


Implementing Agency: Govt (AUDA)

Development Model : TP

Scheme, Gujarat State

Investor : Developer Entity

(Land Owners + Developers)
Implementing Agency: Govt (IRSDC)

Development Model : PPP (land Model: NA

leased to developer for 45 years, ownership with govt.) Investor : IRSDC + Developer (DDA)
Implementing Agency : Govt. Investor : (DDA)

Note: Delhi's TOD Policy follows a similar model as the TP Scheme, however this is a recent development and the framework was in place only years after this proposal came out.

Figure 6 TOD Project Analysis

\subsection{Scoring of Projects}

\begin{tabular}{|c|c|c|c|c|c|c|c|}
\hline \multicolumn{3}{|c|}{ AHMEDABAD } & & \multicolumn{4}{|c|}{ HABIBGANJ } \\
\hline \multirow{3}{*}{$\begin{array}{l}\text { Pre- } \\
\text { Planning } \\
\text { (5- Points) }\end{array}$} & Access & $\checkmark$ & 1.66 & \multirow{3}{*}{$\begin{array}{l}\text { Pre- } \\
\text { Planning } \\
\text { (5- Points) }\end{array}$} & Access & $\checkmark$ & 1.66 \\
\hline & Density of Context & $\checkmark$ & 1.66 & & Density of Context & $\checkmark$ & 1.66 \\
\hline & Single Ownership & $x$ & 0 & & Single Ownership & $\checkmark$ & 1.66 \\
\hline \multirow{5}{*}{$\begin{array}{l}\text { During- } \\
\text { Planning } \\
\text { (5- Points) }\end{array}$} & Higher FAR & $\checkmark$ & 1 & \multirow{5}{*}{$\begin{array}{l}\text { During- } \\
\text { Planning } \\
\text { (5- Points) }\end{array}$} & Higher FAR & $\checkmark$ & 1 \\
\hline & Block Size & $\checkmark$ & 1 & & Block Size & $\checkmark$ & 1 \\
\hline & Pedestrian Grid & $\checkmark$ & 1 & & Pedestrian Grid & $x$ & 0 \\
\hline & Public Spaces & $\checkmark$ & 1 & & Public Spaces & $x$ & 0 \\
\hline & Mix of Uses & $x$ & 0 & & Mix of Uses & $\checkmark$ & 1 \\
\hline \multirow{3}{*}{$\begin{array}{l}\text { Post- } \\
\text { Planning } \\
\text { (5- Points) }\end{array}$} & Innovative Financing & $\checkmark$ & 2.5 & \multirow{2}{*}{$\begin{array}{l}\text { Post- } \\
\text { Planning } \\
\text { (5- Points) }\end{array}$} & Innovative Financing & $\checkmark$ & 2.5 \\
\hline & Institutional Setup & $\checkmark$ & 2.5 & & Institutional Setup & $x$ & 0 \\
\hline & & & $\begin{array}{l}12.33 \\
=\mathbf{8 2} \%\end{array}$ & & & & $\begin{array}{l}10.5 \\
=70 \%\end{array}$ \\
\hline \multicolumn{4}{|c|}{ KARKARDOOMA } & & & & \\
\hline \multirow{3}{*}{$\begin{array}{l}\text { Pre- } \\
\text { Planning } \\
\text { (5- Points) }\end{array}$} & Access & $x$ & 0 & & & & \\
\hline & Density of Context & $x$ & 0 & & & & \\
\hline & Single Ownership & $\checkmark$ & 1.66 & & & & \\
\hline \multirow{5}{*}{$\begin{array}{l}\text { During- } \\
\text { Planning } \\
\text { (5- Points) }\end{array}$} & Higher FAR & $\checkmark$ & 1 & & & & \\
\hline & Block Size & $\checkmark$ & 1 & & & & \\
\hline & Pedestrian Grid & $\checkmark$ & 1 & & & & \\
\hline & Public Spaces & $\checkmark$ & 1 & & & & \\
\hline & Mix of Uses & $\checkmark$ & 1 & & & & \\
\hline \multirow{3}{*}{$\begin{array}{l}\text { Post- } \\
\text { Planning } \\
\text { (5- Points) }\end{array}$} & Innovative Financing & $x$ & 0 & & & & \\
\hline & Institutional Setup & $x$ & 0 & & & & \\
\hline & & & $\begin{array}{l}6.66 \\
=\mathbf{4 4} \%\end{array}$ & & & & \\
\hline
\end{tabular}

Figure 7 Scoring of Projects 


\subsection{Observations}

- $\quad$ Based on the scoring, Ahmedabad CBD qualifies as a High Probability TOD and fares very well in all phases, with an overall score of $82 \%$. Although, multiple ownership of land is seen as a limitation here, Ahmedabad's bottom-up land assembly mechanism, i.e. the TP Scheme, outweighs the project delays caused by land pooling and plot reconstitution by AUDA. However, being a CBD proposal, the project cannot be seen as a complete TOD project due to the predominance of commercial over residential and recreational uses.

- Habibganj Station, Bhopal also qualifies as a High Probability TOD, with a score of $70 \%$, primarily due to its location in a low density area and the PPP Model of Development devised in its financing. However, the design needs serious considerations for it to become TOD-friendly. Ideas of walkability and public spaces are yet to be reflected in the masterplan.

- Kakardooma Metro Station Delhi, on the other hand, despite faring extremely well in the design phase, gets classified as Medium Probability TOD (51\%), primarily due to its location in a busy and congested part of the city and the lack of financing and institutional mechanisms to ensure its implementation. Its exceptional design principles not only focus on high density development and public spaces but also advocate an appropriate mix of uses with housing for the Economically Weaker Section (EWS) category. However, this project has the potential to fare as a very high potential TOD project if Delhi TOD Policy's institutional setup (released a few years after the Karkardooma proposal came out in public domain) can be applied and Private Developers can be incentivised to develop this piece of public land.

\section{Conclusions}

The paper demonstrates equal significance of all three phases in the planning and execution of TODs. Karkardooma in Delhi is a classic example of how design alone may not be enough to implement TOD on ground. Theoretical design aspects of TOD aside, context and finance become the most important factors for decision-makers, who also have a responsibility towards existing populations and may not want to tamper with their day-to-day activities. This also indicates the inadequacy of highly complex TOD Design Scoring exercises to evaluate TOD projects.

Therefore, TOD may be more easily implementable in areas with low population, i.e. the peri-urban regions (as in the case of Habibganj), compared to dense urban cores. However, this has to be complemented with adequate design. In contexts like Ahmedabad CBD and Karkardooma, special care has to be taken to not disrupt everyday life and therefore may be a slower process, yielding dividends gradually over a span of decades. This time factor will have to be foreseen before dense urban regions are picked for TOD, unlike in the case of Habibganj wherein the land is leased for a small period of 45 years to the developer.

Since India is still struggling with various land assembly mechanisms in both greenfield and brownfield areas, projects like Karkardooma and Habibganj are low-hanging fruits because of public land ownership, and therefore must be on government's priority list. Projects like CBD, although follow the right approach in land assembly, still require plenty of public 
consultations and workshops with plot owners, apart from various other time and resourceintensive events to garner consensus and attract investment from developers. For Indian cities to reap instant benefits from TOD, strategic selection of potential and the most suitable station areas is the key.

\section{References}

AGARWAL, O. P., KUMAR, A. \& ZIMMERMAN, S. 2019. Emerging Paradigms in Urban Mobility : Planning Financing and Management, Cambridge, USA, John Simpson.

AUDA 2015. Comprehensive Development Plan 2021 (Second Revised). In: (AUDA), A. U. D. A. (ed.). Ahmedabad.

BALLANEY, S. 2008. Making Urban Planning Work: Town Planning Mechanism in Gujarat, India. In: INSTITUTE, W. B. (ed.). Washington DC.

BIN, T. S. \& NAIDU, V. L. 2014. Public Housing in Singapore: Examining Fundamental Shifts. In: LEE KUAN YEW SCHOOL OF PUBLIC POLICY, N. (ed.). Singapore.

CERVERO, R. \& KOCKELMAN, K. 1997. Travel Demand and the 3 D's: Density Diversity and Design. Transportation Research Part D: Transport and Environment, 2, 199-219.

CERVERO, R. \& MURAKAMI, J. 2008. Rail + Property Development: A model of sustainable transit finance and urbanism. In: TRANSPORT, U. B. C. F. F. U. (ed.). Berkeley.

CHITLANGIA, R. 2019. Five Delhi Metro stations shortlisted for transit-oriented development. Hindustan Times.

DAS, M. 2019. IRSDC to categorise railway stations for redevelopment and modernisation. Business Line, March 25, 2019.

DDA 2012. Transit Oriented Development- Policy, Norms and Guidelines. In: UTTIPEC (ed.). New Delhi: Delhi Development Authority.

DDA 2015. Proposed Transit Oriented Development (TOD) Regulations as envisaged in Transportation Chapter of MPD notified vide S.O. no. 1914 (E) dated 14.07.2015. In: AUTHORITY, D. D. (ed.). New Delhi.

DUTTA, A. 2015. New Urban Utopias of Postcolonial India: 'Entrepreneurial Urbanization' in Dholera Smart City, Gujarat. Dialogues in Human Geography, 5, 3-22.

EMBARQ 2011. Towards a Walkable and Sustainable Bangalore : An Accessibility Project for Indirangar Metro Station. In: INSTITUTTE, W. R. (ed.). Bnagalore.

ITDP 2017. TOD Standard. 3rd Edition. New York.

JOSHI, R., JOSEPH, Y., PATEL, K. \& DARJI, V. 2017. Transit-Oriented Development: Lessons from Indian Experiences. In: CENTRE FOR URBAN EQUITY (CUE), C. U. (ed.). Ahmedabad, India.

MATHEWS, R., PAI, M., SEBASTIAN, T. \& CHAKRABORTY, S. 2018. State-led alternative mechanisms to acquire, plan and service land for Urbanisation in India. In: INSTITUTE, W. R. (ed.). New Delhi.

MOSPI, G. O. I. 2015. Total Registered Motor Vehicles in Million Plus Cities. In: 2016, M. V.-S. Y. B. I. (ed.). New Delhi.

MOUD 2017. National Transit Oriented Development (TOD) Policy. In: (MOUD), M. O. U. D. (ed.). New Delhi: MoHUA.

NAIR, R. 2016. RFCTLARR Act, 2013 : Overview of Recent Developments. ASCI Journal of Management.

NATIONS, U. 2018. World Urbanisation Prospects: The 2018 Revision. In: DEPARTMENT OF ECONOMIC AND SOCIAL AFFAIRS, P. D. (ed.).

RANGWALA, L., K., S. K., MULUKUTLA, P. \& KULKARNI, S. 2014. Rethinking Off-Street Parking Regulations around Station Areas in Mumbai: Inputs into the Mumbai Development Plan 2014-2031. In: INSTITUTE, W. R. (ed.).

ROWCHOWDHURY, A., NASIM, U. \& DUBEY, G. 2018. PAMPering Cities: How to manage urban India's parking needs. In: (CSE), C. F. S. A. E. (ed.). New Delhi.

SABIKHI, R. 2016. Warped Priorities Dictate Future Development In Delhi. Business World. 
SUZUKI, H., CERVERO, R. \& IUCHI, K. 2013. Transforming Cities with Transit : Transit and Land Use Integration for Sustainable Urban Development, Washington D.C., The World Bank. TNN. 2017. Slow groundwork delays Central business district skyscrapers The Times of India. UNITED NATIONS 2019. World Population Prospects 2019: Highlights. In: DEPARTMENT OF ECONOMIC AND SOCIAL AFFAIRS, P. D. (ed.). New York: United Nations.

WAHI, N. 2018. How Central and state governments have diluted the historic land legislation of 2013 The Economic Times. 